\title{
Student Perceptions and Institutional Targets: the matches and mismatches of financial bursary support
}

\author{
Marcellus Mbah (Nottingham Trent University); Sue Eccles (Bournemouth \\ University); Simon Frost (Bournemouth University)
}

\begin{abstract}
Bursary support in Higher Education (HE) helps to enable students from widening participation (WP) backgrounds to more fully engage with their university experiences on an equal basis to their peers. But whilst such support is intended to enhance access to HE, aid retention and increase academic success (which can be monitored using existing institutional data), less is understood about student perceptions of this support. To address this gap, studies are required that investigate both the student experience of receiving financial assistance and, crucially, the mode by which that assistance is delivered: the latter impinging directly on student experience. The survey in this paper used a single UK university in which a range of financial assistance is provided, including bursary funds and hardship funds, and where a significant proportion of students are from WP backgrounds. A mixed methods approach was adopted comprising an online questionnaire, in-depth semi-structured interviews and focus groups. The findings suggest that receiving financial assistance has a positive impact. However, three areas emerged where the administration and impact of financial support could be improved: pre-financial support to better ascertain the nature and level of bursary and any non-financial complementary support required by individual students; embedded financial mentoring to help students with budgeting and addressing any non-financial issues such as stress, academic performance and low confidence; and postfinancial guidance to support students towards longer-term financial independence and stability. Improvements in student support could be achieved through strategic amendments to current provision that addresses the three areas noted but, as this study suggests, perhaps more-so by considering the modality of the bursary provision.
\end{abstract}

Key words: Financial Support, Higher Education, Widening Participation

\section{Introduction}

The study captured in this paper address the subject of financial support and its impact on students, especially those from widening participation (WP) backgrounds. Recent studies around this highly topical subject have captured controversies and presented a wealth of evidence (O’Brien, 2015; Hoare and Lightfoot, 2015; Malcolm, 2015; OFFA, 2010), each commenting in their own way on access to HE, retention, wellbeing, success and employability. From a policy perspective, the primary role of the institutional financial bursary is to enable recipients from WP backgrounds and/or those who are experiencing financial hardship to participate in higher education on a more equal basis to their peers (McCaig et al., 2016). A report that captures the outcomes from OFFA's monitoring of access agreements for 2015-16 reveals that "young people from disadvantaged backgrounds are still nearly two and a half times less likely to enter higher education than their more advantaged peers (OFFA, 2017, p.13). By narrowing the financial gap, access to higher education can be engendered and students from low income households will supposedly more 
fully engage with their university studies and other campus experiences, which in turn should narrow the social gap, leading to more confident, knowledgeable and employable graduates.

The provision of financial support for HE students in the UK has undergone a series of changes over the past few years. Informed by the HE Act of 2004, the 2006 reforms on student finance made provision for students to take up income-contingent loans to pay the course fee charged to them. Tuition fees were capped at $£ 3000$ and, at the time, were variable. This change from an initial $£ 1000$ per year to be paid by students towards the cost of their studies in the 1990s was intended to render the income of universities sustainable with less dependence on public resources (Browne Report, 2010). As part of other government initiatives to reduce public funding, students were required to bear more responsibility towards the costs of their studies, and tuition fees increased up to £9000. In response to this, a new system for HE funding was implemented that would provide additional financial support to students from low income backgrounds through the National Scholarship programme (BIS, 2011). When the programme ceased after 2014/15, more attention was placed on the negotiated Fair Access Agreement whereby universities are required to implement additional and valuable ways of widening access and broadening the choice students make about HE. Thus, HE institutions that charge high tuition fees are expected by OFFA, the independent regulator established by the government in 2004, to ensure that they have mechanisms such as bursaries in place to attract disadvantaged students, and to support them during their study.

To optimise impact, administering institutions monitor their bursaries to see if they serve the intended purpose. A literature review commission by OFFA in 2015 on the impact of institutional bursaries or financial support on access to HE suggested that, although some students felt that financial support affected their decision about HE enrolment and choice of university, it was not the most significant determinant (Nursaw Associates, 2015). This is corroborated by an earlier report in a study carried out by Bowes et al. (2014), which suggested that the extent to which financial support or bursaries can make a difference is often determined by other dynamics such as the relevance of the programme of study, its likelihood of leading to a job, the geographical location of the institution and perhaps the possibility of attending university from home. Whilst the suggestion is that institutional financial support has the potential to impact on a student's choice of university, and aid retention, wellbeing and success, there is limited research that addresses how these potentials can be maximised in conjunction with other variables (Nursaw Associates, 2015).

Furthermore, the situation is compounded when we consider that these variables consist, too, of the mode by which financial assistance is provided. Whilst HEIs in the United Kingdom have adopted different ways of administering financial support, the following are some of the prominent modes in England:

- Traditional cash bursaries: These are direct cash awards to students to support their studies or provide help with standards of living. In some universities, the revised NSP in 2014-15 are awarded as a fixed cash bursary.

- Branded cash bursaries delivered through a wider structure of support: These are bursaries intended for different demographics within the student body such as mature students, students from household with less than £25,000 annual income, first in family to attend university, students with additional learning needs/disability, black and minority ethnic groups, students from low participation neighbourhoods, care experienced and carers. These include placement opportunity funds; hardship funds; the care leaver's bursary; maintenance bursaries; accommodation crisis funds; fee waivers and fee discounts. 
- Targeted support bursaries with a specific branded identity: These are institutionally branded bursaries that, in addition to a possible cash bursary, provide targeted 'in kind' packages to reinforce retention, progression, and success in graduation and toward employment. Such packages can include everything from discounts on texts books, transport, or child care, to the provision of learning resources such as a 'free' pre-loaded tablet for the enrolling target student. An example of this is the ASPIRE scheme provided by a number of HEIs in England in conjunction with the academic book retail corporation John Smith's (Frost, 2015)

Not only is the provision of assistance important to students, but the way in which it is provided is important too. Research needs to be sensitive to this modal element, which unfortunately is not always seen by students who are merely aware that they receive 'support'. Often, students do not know what support they are entitled to until they arrive at an institution (Corver, 2010) and, once underway, students are not always aware that the additional aid is being provided by their university (Callender et al., 2009; Harrison et al., 2007). The problem is that the complexity of financial assistance is rarely recognised and, from the students' perspective, the assistance is often seen as an undifferentiated provision of generically termed 'support'. As a first step, therefore, the current study chose to follow student perceptions and investigate assistance as though it were a broad generic support. From analysis of the findings - of both positive and negative reactions to financial support suggestions could then be made for solutions that achieve their aims by addressing the modality of provision. By considering this additional aspect, universities could do more to ensure that the opportunities clearly created by financially supporting WP students are made even more sustainable.

\section{Methodology}

This paper draws on an institutional case study of a university in the south of England. It aligns with similar studies that have investigated university financial support and embraces different perspectives such as access to HE (Cover, 2010), student retention (Hoare and Lightfoot, 2015), student success (Nursaw Associates, 2015; Malcolm, 2015), progression (O’Brian, 2015), mature students (Newson, McDowall and Saunders, 2011; Creedon, 2015) and attitudes to debt (Marriot, 2007). A single institutional approach has been shown to help with the understanding of a broader subject (Yin, 2013) such as the impact of institutional financial support on students accessing and succeeding in Higher Education. A mixed methods approach was adopted in this study, which included a survey to capture data from a wide range of students, four semi-structured interviews and two focus groups. A questionnaire was administered using an online survey tool (Bristol Online Survey), which captured closed and open-ended responses. The design and content of the survey was adapted from a project commissioned by OFFA that established a set of measures used by five universities in the UK to collect data and report on the impact of financial support on students' success and wellbeing (McCaig et al., 2016). A total of 3,163 students were contacted and asked to complete the survey as follows: 1,934 Bursary students; 745 recipients of Hardship Fund support; 414 recipients of Emergency Loans and 70 Placement students receiving Hardship Fund support. Out of the 3,163 students initially contacted, a total of 612 completed questionnaires were received. The number of respondents under each widening 
participation (WP) flag are represented in figure 1. It is worth noting that respondents could be in more than one WP group.

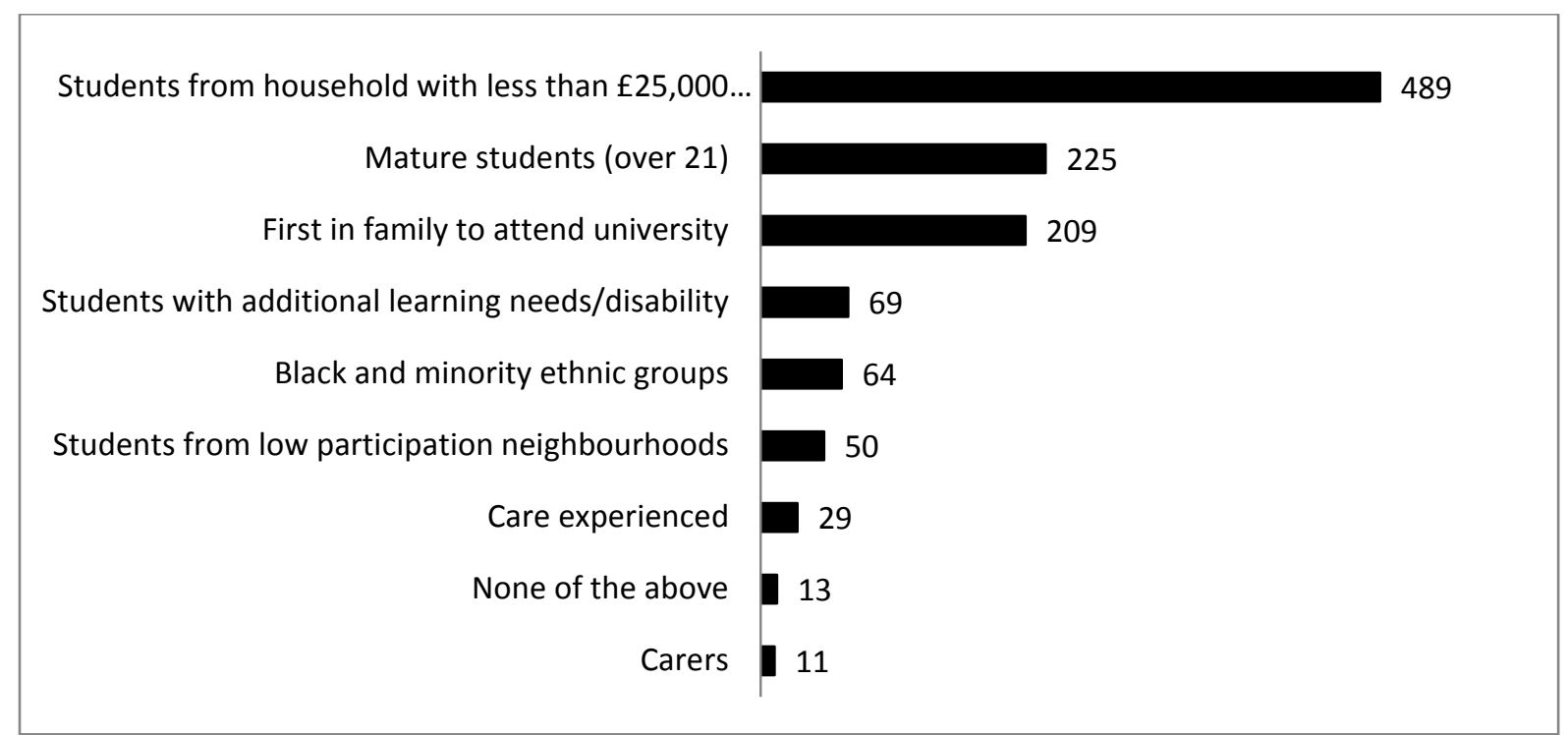

Figure 1: Number of survey respondents under each WP group

The interview and focus group participants were volunteers who had responded via the Bristol Online Survey to the request for further participation in the study. Semi-structured interviews with two First Year, one Second Year and one Placement level students took place and these were interactive and open-ended in nature (Yin, 2013). These allow the interviewer opportunities for probing beyond the structured predetermined questions, affording the research more space for clarification and elaboration. In addition, two mini-focus groups took place, comprising three students in each group. All the students in the focus groups were beneficiaries of university bursaries. These focus groups provided an opportunity to generate richer and more detailed data by probing into the survey results (Kitzinger, 1995; Morgan, 1996). They also provided a forum whereby participants were encouraged by their peers to articulate and share their ideas and experiences in an open discussion. The number of semistructured interviews and focus groups, as well as their composition, was subject to the availability of the student participants. It was also useful to capture perspectives from students who belong to different university levels as they are likely to have varied experiences.

Whilst the Bristol Online Survey was used to generate simple descriptive analysis, audio recordings of the interviews and focus groups were transcribed and analysed thematically (Aronson, 1995; Boyatzis, 1998). Thematic analysis in this instance entailed the identification of themes or patterns within data, coding the themes or patterns, combining the same or similar themes or pattern, and cataloguing the themes or patterns in order to arrive at meaningful findings (Fereday and Muir-Cochrane, 2006; Aronson, 1995). In the process of making the most out of the thematic analytical approach, all recorded interviews were transcribed and proof read to make sure the transcriptions were consistent with the recordings. It is worth noting that the survey also captured some open ended responses and 
these, too, were analysed thematically. The themes that emerged from the analysis are discussed in the subsequent sections.

\section{Findings}

Given that the aim of this study was to explore students' experiences and perceptions of the impact of the university's financial support on a range of areas, the following insights can be drawn from the data:

\section{Perceptions of receiving university financial or bursary support}

To identify what recipients considered to be the benefits of receiving financial or other bursary support, respondents were asked what would have happened if they had not received support. A total of 469 open ended responses were received and thematic analysis revealed recurrent themes that include: 'debt', 'poor living', 'dropout', 'work', 'financial pressure' and 'lack of access to university'. The frequency distribution of responses under each theme is as follows:

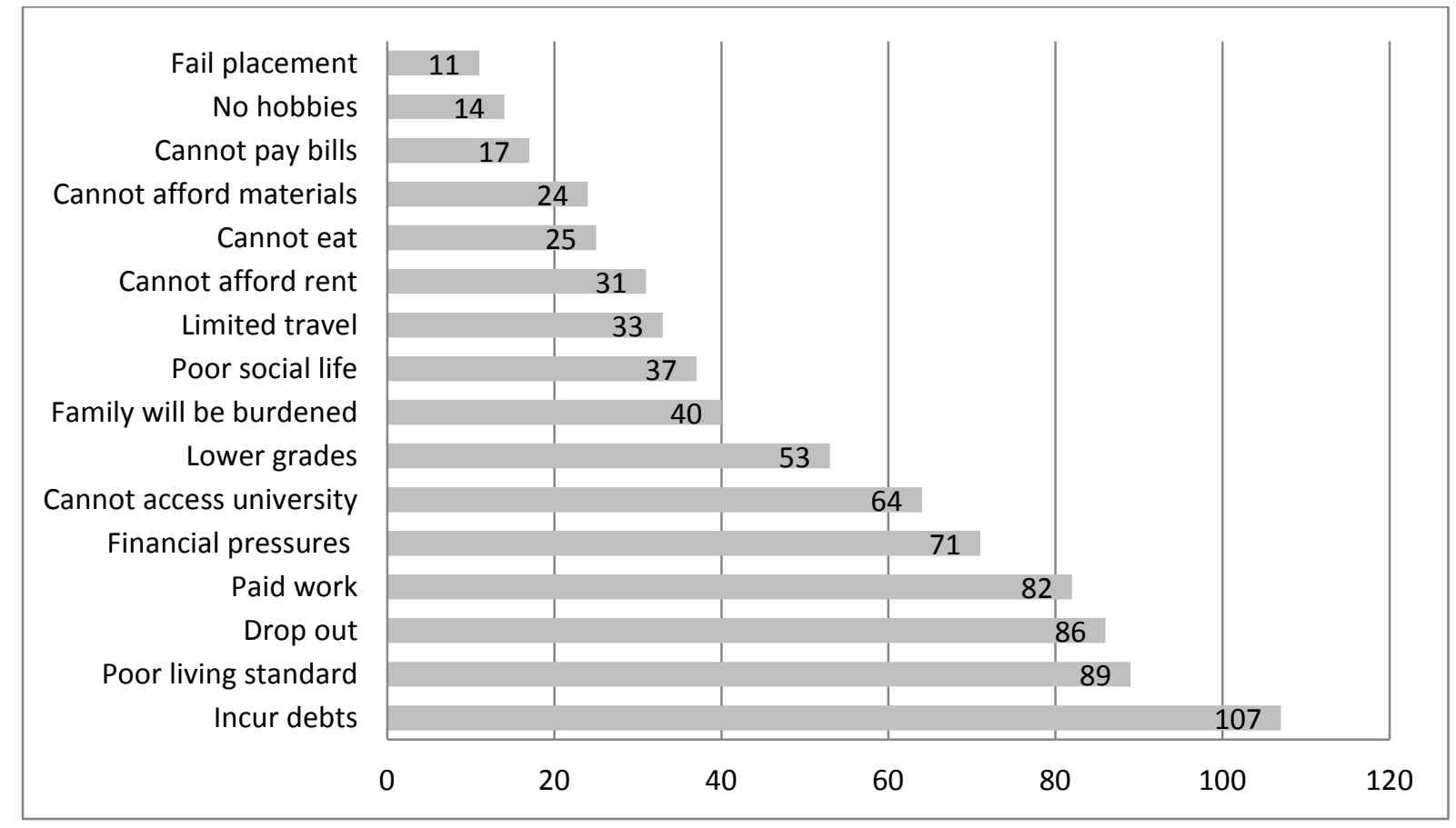

Figure 2: What would have happened if respondents had not received financial support/bursaries

Additional comments from some of the survey respondents reveal further insights into the impact or absence of financial support:

\begin{tabular}{|l|l|}
\hline \multicolumn{1}{|c|}{ Well-being } & \multicolumn{1}{|c|}{ Retention } \\
\hline $\begin{array}{l}\text { "It has made my university time more } \\
\text { pleasant"(WP flag: Student from household } \\
\text { with less than £25,000 income) }\end{array}$ & $\begin{array}{l}\text { "I would probably have had to leave uni and } \\
\text { consider full time work to survive"(WP flag: } \\
\text { Student from household with less than } \\
\text { E25,000 income) }\end{array}$ \\
$\begin{array}{l}\text { "It has allowed me to enjoy student life, and } \\
\text { enjoy time with my friends" (WP flag: First in } \\
\text { family to attend university) }\end{array}$ & $\begin{array}{l}\text { "Being able to afford basic living items } \\
\text { helped me to stay in the university" (WP }\end{array}$ \\
\hline
\end{tabular}




\begin{tabular}{|c|c|}
\hline $\begin{array}{l}\text { "It allowed me to participate in all aspects of } \\
\text { university life, particularly the sporting side" } \\
\text { (WP flag: Student from household with less } \\
\text { than } £ 25,000 \text { income) }\end{array}$ & $\begin{array}{l}\text { flag: Mature student) } \\
\text { "I genuinely do not know how I would have } \\
\text { coped had the fund not have been available" } \\
\text { (WP flag: Mature student) }\end{array}$ \\
\hline Access & Success \\
\hline $\begin{array}{l}\text { "Without this bursary I would not have been } \\
\text { able to attend university" (WP flag: Mature } \\
\text { student) } \\
\text { "It did reduce my anxiety about surviving at } \\
\text { Uni by a massive deal, since before I even } \\
\text { applied for Uni, I wasn't going to go through } \\
\text { with it not knowing how I would pay to live" } \\
\text { (WP flag: First in family to attend university) }\end{array}$ & $\begin{array}{l}\text { "It meant I could spend more time studying } \\
\text { instead of working, which has helped me } \\
\text { achieve a first overall last semester" (WP } \\
\text { flag: Student from a low participation } \\
\text { neighbourhood) } \\
\text { "Allowed me to put everything I could into } \\
\text { my studies and getting the best possible } \\
\text { grades for myself"(WP flag: Care } \\
\text { experienced) }\end{array}$ \\
\hline Placement/Employability & Financial Security \\
\hline $\begin{array}{l}\text { "It helped me when I was struggling to } \\
\text { support myself whilst doing part of my } \\
\text { placement abroad"(WP flag: Student from } \\
\text { household with less than £25,000 income) } \\
\text { "It helped me to eat for an extra week while } \\
\text { on placement"(WP flag: Carer) } \\
\text { "I would not have been able to take a } \\
\text { placement year out in industry"(WP flag: } \\
\text { Student from household with less than } \\
£ 25,000 \text { income) }\end{array}$ & $\begin{array}{l}\text { "I would have put a financial strain on my } \\
\text { family" (WP flag: Student from household } \\
\text { with less than £25,000 income) } \\
\text { "I probably would have been stressed } \\
\text { worrying about money a lot of the time and } \\
\text { not been able to enjoy myself"(WP flag: } \\
\text { Student from household with less than } \\
\text { £25,000 income) } \\
\text { "I would have struggled to budget all } \\
\text { the expenses that come from living away } \\
\text { from home, especially in the 2nd year" } \\
\text { (WP flag: First in family to attend } \\
\text { university) }\end{array}$ \\
\hline
\end{tabular}

Table 1: Comments from some respondents that reveal insights into the impact or absence of financial support

As evident in the comments above, the provision of financial support has significant impact at a time when students experience financial pressure (Malcolm, 2015; Hoare and Lightfoot, 2015). Faced with increasing economic challenges, as well as financial uncertainties, many students have difficult choices to make on entering HE. For some students, such as carers and mature students, financial demands are even greater as they are likely to have one or more dependents (Creedon, 2015) and student loans may not provide sufficient income for these additional responsibilities. Whilst one option may be to choose part-time study, this can increase the duration of the course that may impact on other personal commitments and on family life (Butcher, 2015b).

Managing financial constraints amidst conflicting demands can make the mature student's academic life a continuous struggle (Newson et al. 2009). Other categories of students from disadvantaged backgrounds, too, have had to undertake part time work as a 
primary means to secure more income, prevent additional debt and cover essential living costs (Nursaw Associates, 2015; Harrison and Chudry, 2011; Moreau and Leathwood, 2006; Christie, Mumro and Retting, 2001; Metcalf, 2005). Whilst part-time work may have advantages in terms of graduate employability (Harrison and Chudry 2011; Callender, 2008; McGregor, 2015), it limits the time a student spends in study and social activities, and this could cause anxiety, and negatively affect retention and academic performance ( $\mathrm{Ji}$ and Zhang 2011; McGregor, 2015). Given that debt from student loans is likely to continue to rise as fees increase, students who are debt-averse will be increasingly obliged to undertake part-time work if they cannot get any other financial support (Callender, 2008). The absence of sufficient financial support and part-time work may lead to excessive debts that may also influence early withdrawals or poor academic attainment (National Audit Office, 2007; Davies and Elias, 2003; Quinn et al., 2005). Bowes et al. (2014) argued that having the required financial support in the form of university bursaries or financial support can help to free up time from part-time work, so that beneficiaries can fully commit and engage in academic activities.

The 'Pound in your Pocket' report from the National Union of Students (NUS, 2012) underscored that many students are at the brink of dropping out due to financial difficulties. This assertion is supported by a previous study conducted by Marriott (2007), which noted that some students, particularly those from disadvantaged backgrounds, find the burden of debt so great that dropping out of university is sometimes the only reasonable course of action. A study by Creedon (2015) examined the impact of financial constraints on mature students at one institution and found serious challenges to academic engagement as well as to social integration (though the latter was also an effect of the lack of commonality between mature student and school leavers), and highlighted the negative effects on the mature students' home life, health, wellbeing and ability to remain focused and determined.

As the evidence accumulates, it is becoming a truism that financial support can mitigate the challenges to WP students and to others, so far outlined. Yet this study maintains that the discrepancy in criteria between institution and student end-user may still be causing friction at the point of delivery - unnoticed by previous studies - and that the institution's sense of having fulfilled its aims may not match students' sense of their needs being met.

\section{The impact of financial support/bursary schemes: contradictory views}

Despite a majority of respondents in this study asserting that financial or bursary support at the university made a positive difference, there were a few telling exceptions, as the following comments from participants illustrate:

"If I had not received financial support, I would have carried on with my study at the University because I'd already chosen it; I wouldn't have dropped out but it would have definitely affected my way of life"

"The fact is, when you've started, does it make sense to drop out? How much you are going to lose anyway... debt everywhere" 
"It didn't really help me in terms of the course. May be indirectly, because it helped my stress levels, and then that can help me do better at the university"

"I didn't receive enough money to have any real impact. It just covered my water bills"

“The financial support didn't particularly help me”

Although previous studies reveal that financial support for students can have a positive effect on different areas of the student journey, the context of this assertion needs further scrutiny. For example, it has been reported that many students from disadvantaged backgrounds demonstrate resilience, and progress through their studies despite financial hurdles (Harrison and Chudry, 2011). Wray et al. (2014) noted that one reason for the resilience might be that student who have taken a hard, objective look at their financial limitations prior to commencing $\mathrm{HE}$ are more emotionally prepared to confront the ensuing challenges. This determination in the face of challenges may be more apparent in mature students or students from disadvantaged background, who may have already been accustomed to thriving in the face of difficulties. Whilst financial support can enhance retention of students from low income backgrounds, it is not necessarily the only or main determinant of retention (Creedon, 2015; Tinto, 1993). Tinto (1993) noted that these students would have made hard decisions regarding their study that do not exclusively depend on finance. They may consider the negative fallout of dropping out, and that debts already incurred are outweighed by the advantages derived from yet greater debt required to stay on the course.

Whilst financial support may help level the playing field for some students (Hoare and Lightfoot, 2015; McCaig et al., 2016), this may not exclusively be dependent on the actual financial provision per se but on its 'ripple' effect. Though students in receipt of bursaries could be assumed to have fewer financial worries, it may enable them more importantly to enjoy the social and cultural opportunities available to all students (O'Brien, 2015). Similarly, it has been noted that a range of other factors can play a significant role, not only as key determinants of access to, progression through and success in HE, but also in increasing the impact of financial support (Thomas, 2015). Corroboration for this premise comes from a study carried out by Bowes et al. (2014), which suggested that the extent to which financial support or bursaries can make a difference is often determined by other dynamics such as the relevance of the programme of study, its likelihood of leading to a graduate job, the geographical location of the institution and, perhaps, the possibility of attending university whilst living at home.

Similar to the findings of O'Brien (2015), there is evidence from another study conducted by Hoare and Lightfoot (2015) at the University of Bristol to suggest that the provision of financial support or bursaries does not influence withdrawal rates. Whilst both of these studies were carried out in highly selective institutions, they revealed that students with financial support are less likely to withdraw from the university for financial reasons, but are more likely to withdraw for reasons other-than those of finance.

\section{Experiences of challenges and benefits of financial support}


Alongside the benefits of providing financial support to certain categories of students, some challenges were also revealed around information and communication mechanisms, as well as the frequency and method of payment.

Information and communication mechanisms 
A further element explored in this paper's study was how students heard about or became aware of bursary and financial support. Many of the interviewees and focus group participants acknowledged that they only knew about any potential financial support after enrolment or when they were in a crisis situation, as the following interview excerpt amply demonstrates:

Interviewer: "When were you aware of the Hardship Fund? Was it before you applied to come to Uni, or was it when you were already at Uni?"

Martha (first year student who had received Hardship Fund support): “No, it was because at the time we were thinking of renting this house for next year, which we didn't actually rent because it was too expensive, but I'd gone to the University to talk about this and they had said: 'You know you can apply for the Hardship Fund, this is a thing' and they sent me some information about it, and that's how I found out"

Interviewer: "Did you know that there was such a [financial support] opportunity?”

Marcus (placement student who had received Placement Fund support): "I didn't know until I asked though, so when I found out that I was likely not to be paid for the whole of this year I went and spoke to Student Advice and stuff and got good guidance ... really good guidance actually ... the Student Advice, brilliant!! They basically said: 'This is the thing you should be able to apply for, get on and get paperwork done as soon as possible and hopefully you'll get approved for it'”.

When asked if they knew of the existence of bursaries or financial support, prior to commencing their HE courses, 259 survey respondent answered 'yes', while 262 answered 'no'. The majority of respondents (384) acknowledged that they did not know how much financial support they were going to receive from the university. Although a significant number (172) of respondents confirmed, as expected, that information about any of the University's bursary or financial support schemes did influence their decision to go to university, the majority of respondents (390) replied that it did not. This is not to suggest that the support was in any way unwelcome or unnecessary, but it does pin-point how students might only actively seek out financial support when they need it. This could be due to institutional systems acting as obstacles, since such a finding highlights the need not only for HEIs to provide better information about managing finances but also for students to seek advice prior to a 'crisis point'. It also represents the missed opportunity for HEIs caused by thinking merely in terms of flat, generic support.

The practicalities of receiving bursaries or financial support

The operation of financial support schemes will, amongst other things, take into consideration the frequency and method of disbursement. A report to the Office for Fair Access (OFFA) by Nursaw Associates (2015: 4) noted that "the way in which financial support schemes operate may also limit their impact”. Most of the remarks on payment method and frequency centred on the maintenance bursary and the pre-paid card with 
instalments loaded monthly, as is administered at the host university. Suggestions from respondents who needed 
improvement in the frequency and payment methods underscored the most recurrent themes of 'lump sum payment' and 'bank deposit', as illustrated in the following bar charts:

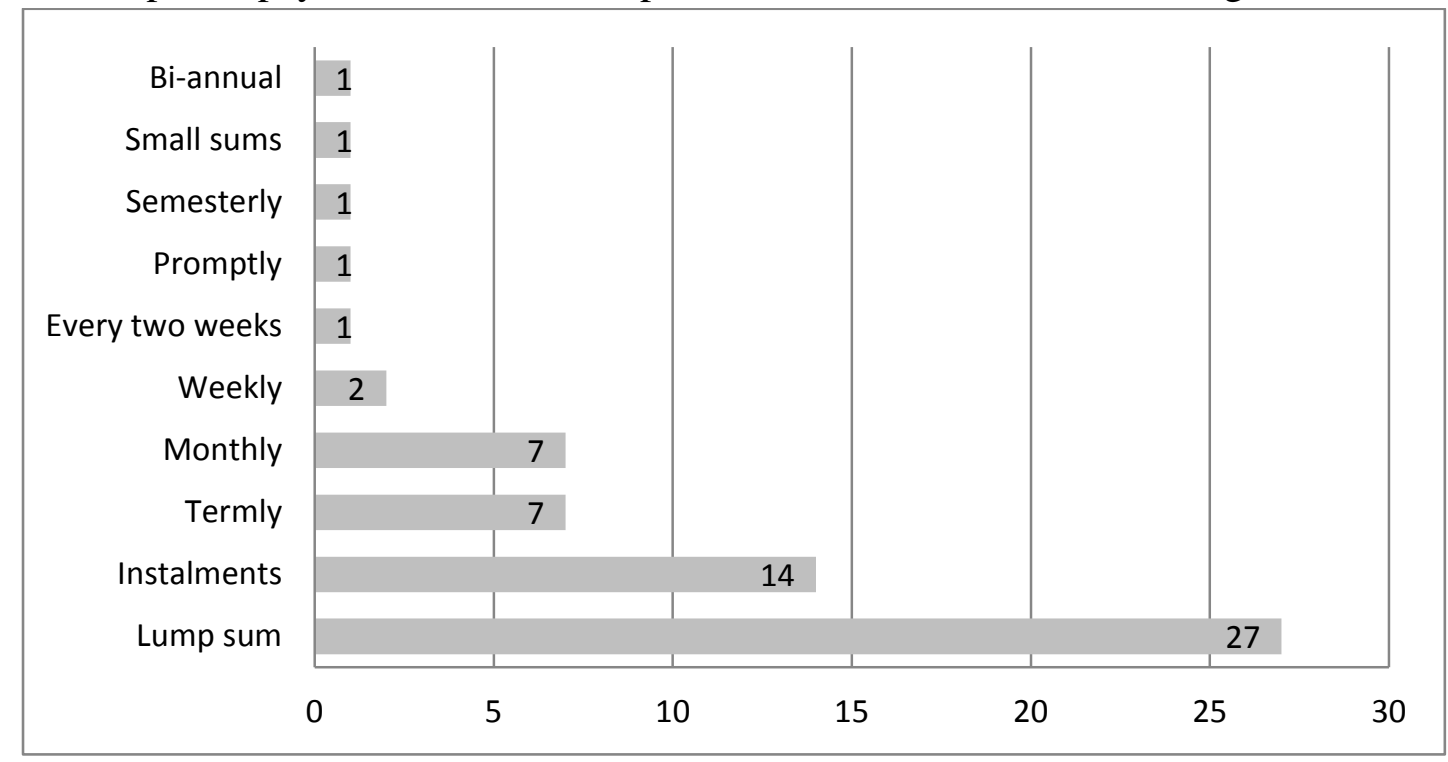

Figure 3: Participants views on preferred frequency of payment

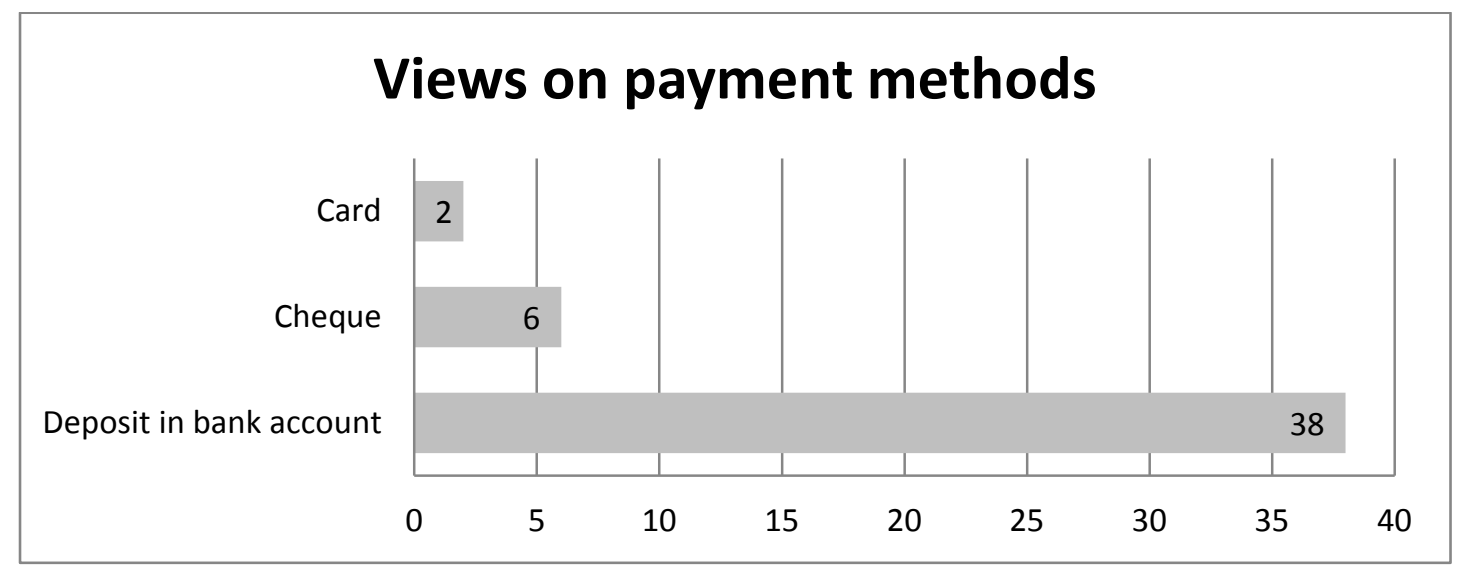

Figure 4: Participants views on preferred payment method

Some reasons advanced by respondents for lump sum payments include:

"Single lump sum would allow me to purchase furniture, pay off large bills etc. It is not the University's place to budget for me"

"A single lump sum would allow me to take better control of and make decisions about my finances over the year. Also I would be able to purchase larger useful items such as household goods (washing machine etc) rather than feeling limited by the smaller instalments which end up being spent on day to day living costs"

"Receiving the money in lump sums would be much more ideal. For example, when looking for second year accommodation, it's very competitive trying to find the nicest place within your budget. Admin/deposit fees are high, and the estate agent is not going to secure the house for you because you'll be able to pay after waiting for 2 more monthly instalments" 
Some reasons advanced for cash deposit into student bank accounts include:

"I would have preferred the money to have been transferred directly into my bank account, so I could use it more effectively. With a pre-paid card, I am restricted to only buying items and cannot therefore transfer money"

"I prefer to budget my money through one account. That's how I've been doing it for a couple years. Having multiple accounts can become somewhat confusing. It would be useful if I had the option to have a lump sum paid into my main account"

"Other universities give money through transfer to student accounts rather than prepaid bursary. Access to cash could've helped me pay bills, money for accommodation next year, some sites won't let me use a pre-paid card as payment”

Whilst some students were happy with their mode of payment, others were not. A university might assume that the money ought to go to cover day-to-day expenses whereas some students prefer or need to spend it on single, larger items. This discrepancy suggests a diverse approach to operationalising financial support schemes, which may be dependent on the need of each student, maturity and relevant experience. One focus group participant, Sharon, who is a beneficiary of the maintenance bursary and about to commence her placement year, argued:

"I think, personally, they need to review the amount they give to individuals, and review how they give it to them. Like Laura was saying, students are different in the sense that they have varied priorities ... he has a family to look after, I don't have a family to look after, how he needs his money is completely different to how I need my money, so there should be a review in the sense that you can't group all students together and expect them to be happy together, because they're all different"

As noted by Sharon, echoing in the words of Laura, the administration of financial support can be productively informed by taking into account the individual needs and preferences of targeted students. However, running a system that sufficiently meets such complex needs would also make any determining of its impact a significant challenge (Callender, 2009). Therefore, to minimize the complexity, it is essential that institutions provide clearly stated objectives and a detailed expression of intended outcomes.

\section{Discussion}

Investigating the impact in HE of financial support and bursaries on access, retention, wellbeing and success, especially for students from WP backgrounds, has produced conflicting findings (O’Brien, 2015; Hoare and Lightfoot, 2015; Malcolm, 2015; OFFA, 2010). Whilst there is literature claiming (limited) efficacy in relation to the impact of bursaries on retention, it is not necessarily the only or main determinant (Creedon, 2015; Tinto, 1993). A few respondents in this study noted that, in the absence of financial support, they would still not consider dropping out. This may be because the burden of debt for students from disadvantaged backgrounds could be exacerbated by dropping out compared to 
seeing the course through. As early as 1993, Tinto noted that this category of students may be more committed to continuing their studies given the hard choices they have already made, which were not exclusively financial but instead predicated on persistence and the anticipated benefits of success. In this light, there are other determinants to student retention and success which can enhance or compliment the impact of financial support (Yorke, 2004; Wray et al., 2013; Thomas, 2015).

It was also evident in the study that financial support did not play a significant part in determining choice of university or programme of study. This is a similar finding to that of Callender and Wilkinson (2013) who found that most respondents did not feel that financial support or a bursary influenced their choice of university. It is clear there are other determinants of choice of university and these may include the location of the university, and its accessibility from home or place of work. Nonetheless, in instances where universities present a clear competitive advantage in the form of a higher bursary value, Corver (2010) noted it may have an impact on choice of university. However, as evident in this study, merely having a competitive bursary package is not enough to attract enrolment communicating this opportunity to prospective students through the right channels or making relevant information easily accessible is equally important.

It can also be suggested on the basis of this study that many of the recurrent themes are intertwined and complex. For example, 'the need for financial assistance' as a motivating factor for students requesting support is directly related to their desire to attain 'financial security'. Furthermore, students' lack of financial security could lead them to incur debts, which, it is reasonable to assert, might prompt levels of anxiety that have negative repercussions on their studies.

The following comment from a respondent illustrates the profound impact financial support can have on a student:

"I was able to purchase food without worrying about going over my overdraft. For this time last year, I had the support of the bursary fund, and this year the support of the hardship fund. I have been able to focus (during those times) much more with my studies and it has helped me feel more comfortable staying in university as a student to complete my studies, with less worries regarding my financial difficulties (although, they still co-exist, the support of the University significantly has reduced them at the time of assistance). I am and will be forever grateful for all the support given to me by the university to help me in such difficult times I have experienced financially"

Whilst some respondents were of the opinion that the level of financial support/ bursary be increased, this was particularly highlighted by mature students who had dependents. Creedon (2015) noted that mature students are more inclined to face greater financial demands compare to their younger peers or those with fewer responsibilities. Irrespective of this, support mechanisms with a focus on mature students are not given the required level of attention (OFFA, 2017). Given the variation in needs between different categories of students - between the needs of, say, mature students and those commencing directly after further education - a more sensitive mechanism ought to be adopted to address and administer financial support. 
Part of this sensitivity clearly includes the way support is provided. Students who would benefit from lump sum payments or cash deposits into bank accounts, as some survey respondents preferred, may well turn out to be mature students; whereas students in their early years may be better served by the branded resource-based provision of textbooks, an electronic tablet and a suit for interviews, as several HEIs adopting the ASPIRE scheme currently provide (Frost, 2015). Given that a range of other factors can help establish or increase the impact of university financial support schemes (Thomas, 2015; Bowes et al., 2014), the following suggestions contain factors which could optimise the impact of financial support/bursary.

\section{Recommendations}

It is clear from this study that students receiving a bursary or other financial support from the university are in a stronger position to better engage with their academic studies and other university activities. However, there is likelihood for provision of financial support or bursary to be perceived as convenient for the university rather than bespoke and managed for the needs of the students. Whilst the modality for managing financial supports can be considered a complex issue, this study advances additional ways these supports could be optimised.

\section{Communication}

There was a clear issue with communication or information dissemination with respect to the different bursary and financial support schemes that universities administer. Many of the students in this study assert that they only became aware of a bursary or financial support scheme in a crisis situation. On this basis, it may be helpful to raise the awareness of prospective and current students to the institution's financial support schemes available to those with financial need. The choice of deploying a branded bursary - either cash based, or resource based - would bring with it the communication advantages that lie in the nature of branding. Many universities consider their financial support schemes as part of their competitive offer which could attract students from low income or less affluent backgrounds (Nursaw Associates, 2015), and attaching these offers as part of the overall university brand would help. Alternatively, that branding responsibility might be taken on collaboratively with a third party providing resources as in the manner of ASPIRE. Getting information on available financial supports to the right targets can be instrumental in maximising the desired return on investment that the university anticipates.

\section{Funding levels}

The level of financial support provided did not fully meet the needs of some students and many of them take on part-time jobs for several hours a week during term time or holiday periods. Some of the respondents noted that working long hours during term time can potentially hamper their ability to continue or succeed in a course. It can be posited that the issue of insufficient financial support is common across the sector (BIS, 2015). However, each institution can make the most of its limited resources. Insufficient levels of financial 
support may be compounded in instances where students have to use the financial assistance provided to support dependents, as revealed in this study. However, universities might consider improvements in the way students' financial needs are assessed that are more sensitive to individual circumstances - for example, distinguishing between mature students with dependents compared to their younger peers without.

Furthermore, value may be added through much more than finance. Centrally organised, either through the HEI or by a third party, the provision of reduced charges for services (such as transport and child care) could be arranged, along with whatever access constraints the HEI chose to adopt. A simple cash bursary would not be able to take advantage of such benefits from centralised scales of economy. The burden of identifying relevant parameters would initially lie with the HEI or third party, drawing on national best practice experience, but in the medium and longer terms benefits would accrue.

\section{Payment method and frequency}

The methods and frequency by which some of the bursary and financial support schemes are administered could be reconsidered to enable students to maximise their benefits. Given that "the way in which financial support schemes operate may also limit their impact" (Nursaw Associates, 2015: 4), it is worth noting the views and experiences of students themselves. In the case of pre-paid cards with instalments loaded monthly (in the case of a Maintenance bursary), the HE needs to be aware that the mode of delivery may be locking in students who would rather have the bursary paid directly to their bank accounts so that they can budget and withdraw cash for recurrent expenditures (which cannot be done with the prepaid card); or alternatively locking in other students would more effectively make use of one lump sum to facilitate expenditure on single, larger items.

Although there are merits with issuing prepaid cards with cash instalments loaded periodically, universities might explore other ways of administering financial aids to students, apart from providing cash, while taking into account the individual circumstances of the students. Distinguishing between the needs and responsibilities of early-year students and of mature students, universities may find that various branded bursaries based on different communities of student, with or without a cash element, are able to offer such differentiated provision whilst avoiding charges of undue bias. Maximising the flexibility available to smartcards could be one way to go in terms of targeting the right communities, while providing learning materials on a tablet and/or support for services such a child care, as in the case of ASPIRE (Frost, 2015), might be another. Whilst limiting student use of the bursary to education-related products and services would remove some of the student's selfdetermination, it would conversely provide a very clear link between financial support and academic success. The responsibility lies with the HE to determine which benefits would be most helpful to which students.

\section{Additional support}

It was evident in the study that financial support is not the silver bullet needed to promote access to HE, retention, wellbeing and success. Similar to the findings of other studies, there 
are non-financial factors that could inhibit or limit the impact of financial support (Tinto, 1993; Yorke, 2004; Wray et al., 2013; Thomas, 2015; Creedon, 2015). Despite adequate financial support, a student can still withdraw from university due to poor academic attainment, health concerns, low morale and lack of social integration. Whilst the provision of financial support may exert a positive ripple effect on these social cultural factors, nonfinancial support could have an equally positive impact. For example, Farenga (2015) noted that academic and pastoral support, as well as embedded mentoring, can enhance the retention and success already achieved through financial support. Such additional, or rather extra-financial support could readily be built into a branded targeted bursary.

To optimise the benefits of an awarded bursary, additional support can be administered at three stages: pre-award, during-the-award, and post-award. Pre-award support should ensure that students can access relevant information, apply it to their own situation, and discover how that situation can be further improved through the extra-financial support available. Embedded mentoring during the period of the award can help the student with budgeting and managing their money, as well as identifying and helping with non-financial issues such as stress, worries, academic struggles and low confidence. Post-award support may help students reflect back on the impact of receiving the bursary and what difference that made, as well as helping them towards longer-term financial independence.

Furthermore, an additional support mechanism that is applicable across all three phases is the aspect of 'belonging', by which is meant the "extent to which students feel personally accepted, respected, included and supported by others" in the institution (Goodenow, 1993). Research (BIS, 2014; Thomas, 2012) has emphasised how creating and nurturing a culture of belonging is the most important factor in improving retention rates and the experiences and success of all students. And there may be good reason for aligning belonging to bursary and financial provision, since Nursaw (2015: 20), following Thomas (2012), found that "financial support [could] nurture [a sense of] belonging and create a relationship between the student and the university and department, for example, by offering books and other materials”. A university branded bursary would certainly be in the best position to respond to such a need.

Whilst it was evident that receiving financial support helped many of the respondents, universities could do more to ensure that the opportunities created are sustainable for students in the longer term. By considering the mode by which financial provision is provided, universities may be better placed to resolve issues raised by this and other similar studies: optimising outcomes for both students and for institutions. However, insightful though the findings of this study might be, it is hampered by two factors. Firstly, the limited sample size and focus on a single institution limit the potential to generalise, and a wider national study would be required. Secondly, and more importantly, a study would be needed in which the issue of modality were embedded centrally in the design phase. To achieve this, a study would be needed comprising institutions from Russell Group, "New Universities” and Post1992 Universities, that would gather data on their use of the three modalities of bursary and financial provision defined as the Traditional cash bursary, the Branded cash bursary delivered through a wider structure of support, and the Targeted support bursary with a specific branded identity. Such a wider, more differentiated study would provide an opportunity for comparative analysis, revealing more precise, extensive implications. 


\section{References}

Aronson, J. (1995) 'A pragmatic view of thematic analysis', The qualitative report, 2(1): 1-3. BIS, (2011) 'Students at the Heart of the System, June 2011', available at: https://www.gov.uk/government/uploads/system/uploads/attachment_data/file/31384/ 11-944-higher-education-students-at-heart-of-system.pdf (Accessed on 15/10/2016)

BIS, (2015) '2010 to 2015 government policy: access to higher education, May 2015', available at https://www.gov.uk/government/publications/2010-to-2015-governmentpolicy-access-to-higher-education (Accessed on 31/12/2017)

Bowes, L, Moreton, R, Thomas, L, Porter, A, Sheen, J and Birkin, G. (2014) Evaluation of the National Scholarship Programme - Year 3: Report to HEFCE by CFE Research and Edge Hill University. Bristol: HEFCE.

Boyatzis, R. E. (1998) Transforming qualitative information: Thematic analysis and code development. Sage.

Browne, J. (2010) 'Securing a sustainable future for higher education: an independent review of higher education funding and student finance', available at: https://www.gov.uk/government/uploads/system/uploads/attachment_data/file/422565 bis-10-1208-securing-sustainable-higher-education-browne-report.pdf (Accessed on the $15 / 10 / 2016)$.

Butcher, J. (2015b) 'Shoe-Horned And Sidelined'? Challenges For Part-Time Learners In The New HE Landscape.

Callender, C. and Wilkinson, D. (2013) 'Student perceptions of the impact of bursaries and institutional aid on their higher education choices and the implications for the National Scholarship Programme in England', Journal of Social Policy, 42(02): 281308.

Callender, C. (2009) Awareness, take-up and impact of institutional bursaries and scholarships in England: Summary and recommendations.

Callender, C. (2008) 'The impact of term-time employment on higher education students' academic attainment and achievement', Journal of Education Policy, 23(4): 359-377.

Christie, H., Munro, M. and Rettig, H. (2001) 'Making ends meet: student incomes and debt', Studies in Higher Education, 26(3): 363-383.

Corver, M. (2010) 'Have bursaries influenced choices between universities?' OFFA Report No AWP359.

Creedon, D. (2015) The Experience of Financial Hardship on Mature Students' Social and Academic Integration.

Davies, R. and Elias, P. (2003) Dropping out: A study of early leavers from higher education. London: Department for Education and Skills.

Farenga, S.A. (2015) 'How going beyond financial support contributes to student success and retention: an institutional case study of the National Scholarship Programme' Widening Participation and Lifelong Learning, 17(3): 60-73. 
Frost, S. (2015) Bespoke Bookselling for the 21st Century: John Smith's and Current UK Higher Education (Project Report).

Goodenow, C. (1993) 'Classroom belonging among early adolescent students: Relationships to motivation and achievement', The Journal of Early Adolescence, 13(1): 21-43.

Harrison, N. and Chudry, F. (2011) 'Overactive, overwrought or overdrawn? The role of personality in undergraduate financial knowledge, decision-making and debt', Journal of Further and Higher Education, 35(2): 149-182.

Harrison, N., Baxter, A., \& Hatt, S. (2007). From opportunity to OFFA: The implementation of discretionary bursaries and their impact on student finance, academic success and institutional attachment. Journal of Access Policy and Practice, 5(1): 3-21.

Hoare, T. and Lightfoot, J. (2015) 'Student funding, student retention and student experiences: perspectives from Bristol', Widening Participation and Lifelong Learning, 17(3): 110-125.

Ji, H. and Zhang, L. (2011) 'Research on college students' stresses and coping strategies', Asian Social Science, 7(10): 30.

Kitzinger, J. (1995) 'Qualitative research. Introducing focus groups', BMJ: British medical journal, 311(7000): 299.

Malcolm, D. (2015) 'Access, retention or success? What problem are we trying to solve with student finance?’ Widening Participation and Lifelong Learning, 17(3): 32-46.

Marriott, P. (2007) 'An Analysis of First Experience Students' Financial Awareness and Attitude to Debt in a Post-1992 UK University’, Higher Education Quarterly, 61(4): 498-519.

McGregor, I.P. (2015) 'How does term-time paid work affect Higher Education students' studies, and what can be done to minimise any negative effects?', Journal of Perspectives in Applied Academic Practice, 3(2).

McCaig, et al. (2016) Understanding the impact of institutional financial support on student success: Phase One Report for the Office for Fair Access, February 2016

Metcalf, H. (2005) 'Paying for university: the impact of increasing costs on student employment, debt and satisfaction’, National Institute Economic Review, 191(1): 106117.

Morgan, D.L. (1996) 'Focus groups', Annual review of sociology,129-152.

Moreau, M.P. and Leathwood, C. (2006) 'Balancing paid work and studies: Working (-class) students in higher education', Studies in Higher Education,31(1): 23-42.

National Audit Office (2007) Staying the Course: The retention of students in higher education. London.

National Union of Students (2012) The Pound in Your Pocket Summary Report, NUS.

Newson, C., McDowall, A. and Saunders, M.N. (2011) 'Understanding the support needs of mature students', Guildford, University of Surrey Publ.

Nursaw Associates (2015) What do we know about the impact of financial support on access and student success? OFFA, April 2015

O'Brien, M. (2015) 'Student finance, progression and'inclusivity': indicative data from the University of Liverpool', Widening Participation and Lifelong Learning, 17(3): 7488.

Office for Fair Access (2017) 'Outcomes of access agreement monitoring for 2015-16', available at https://www.offa.org.uk/wp-content/uploads/2017/06/OFFA-MonitoringOutcomes-Report-2015-16-Final.pdf (Accessed 01/06/2018) 
Office for Fair Access (2010) 'Have bursaries influenced choices between universities?', available at https://www.offa.org.uk/wp-content/uploads/2010/09/Have-bursariesinfluenced-choices-between-universities-.pdf (Accessed 11/10/2016).

Osborne, M., Marks, A. and Turner, E. (2004) 'Becoming a mature student: How adult appplicants weigh the advantages and disadvantages of higher education', Higher Education, 48(3): 291-315.

Quinn, J., Thomas, L., Slack, K., Casey, L., Thexton, W. and Noble, J. (2005) 'From life crisis to lifelong learning', Rethinking working class' drop out'from higher education. York: Joseph Rowntree Foundation.

Thomas, L. (2015) Editorial. Widening Participation and Lifelong Learning, Volume 17, Number 3, October 2015, pp. 5-16

Thomas, L. (2012) 'Building student engagement and belonging in Higher Education at a time of change', Paul Hamlyn Foundation, 100.

Tinto, V. (1993) 'Toward a theory of doctoral persistence', Leaving college. Rethinking the causes and cures of student attrition, pp.230-256.

Wray J, Aspland J and Barrett D. (2014) 'Choosing to Stay: Looking at retention from a different perspective', Studies in Higher Education. 39(9): 1700-1714.

Yin, R. K. (2013) Case study research: Design and methods. Sage publications.

Yorke, M. and Longden, B. (2004) Retention and student success in higher education. McGraw-Hill Education (UK). 
